\title{
IAMJ
}

INTERNATIONAL

AYURVEDIC

MEDICAL JOURNAL

\section{INTERPRETATION AND CO-RELATION OF SAMYAK LANGHAN LAKSHAN IN CHARAK SAMHITA WITH CONTEMPORARY SCIENCES}

\section{$\underline{\text { Akhilesh Kumar Singh }}$}

P.G Scholar, Department of Samhita \& Siddhant, Uttaranchal Ayurvedic College, 17 Old Mussorie Roads, Dehradun, Uttarakhand, India

Corresponding Author: akhileshsingh_2001@,rediffmail.com

\section{https://doi.org/ $10.46607 /$ iamj3508102020}

(Published online: October 2020)

Open Access

(C) International Ayurvedic Medical Journal, India 2020

Article Received: 13/09/2020 - Peer Reviewed: 28/09/2020 - Accepted for Publication: 03/10/2020

\section{(D) Check for updates}

\section{ABSTRACT}

Objective - Ayurveda is the oldest keen knowledge of life sciences, cure and healthcare. The sutras in samhita have to be enlightened in term of modern sciences. This article presents simplified yet scientific decoding of the sign of proper Langhana mentioned in Charak samhita. Methods - Several studies by researchers available on website as Pub med, Google scholar, Scopus, collected to explain different sign of proper Langhana (Fasting) and detail review of different Ayurveda literatures to explore Samyak Langhan Lakshan. Conclusion- fating have a direct and good effect on gastrointestinal colonial bacteria, gastrointestinal reflex, kidney function, hypertension, obesity, mental condition, thermal homeostasis of skin, eating behavior, BMI, Ghrelin hormone and glycogen metabolism. Those all factor is responsible to present the proper sign of complete Langhan.

Keyword: Langhan, Mutra Visharga, Vat Visharga, Tandra, Udagar, Kanth Shuddhi, Swede Jayate

\section{INTRODUCTION}

Among 225 articles searched, 54 were found relevant. These articles are pointing out the close association of Langhana (fasting) for illumination of sign of
Samayak Langhan Lakshan. Samyak Langhana Lakshan mentioned in Charak samhita is well presented in respect of contemporary science. Effect 
of modern fasting on human body is reviewed from literary search. That effects of modern fasting are as similar as Samyak Langhan Lakshan. Charak, sushrut and Vagbhat has explained Langhan in their own words, but all the acharyas have presented approximately same sign of proper Langhan. "Vat MutraPureeshanam Visarge Gatra Laghve / Hruday Udgar Kanth Assya Shudhhau Tandra

Klame Gate // Swede Jate Ruchau Chaiv Khut Pipas Sah Udayel Krutanm Langhanm Aadeshyam Nivyarthe ch Antaratmanee"/l. Charaka Samhita Sutrasthana, 22/34, 35. According to charak, Sign of proper Langhan (fasting) is Vata Mutra Pureesha Visarga or proper excretion of flatus, urine and faeces, Laghava or lightness in body, Hrudaya Shuddhi or Feeling of lightness and purity in heart, Udgara Suddhi and Kanta Suddhi or purity in eructation/burping, Tandra Klame Gate - Feeling of fresh, remove dullness and drowsiness, Swede Jate Appearance of sweat, Ruchau Chaiv - appreciation of taste, Khut Pipas Sah Udaye- Hunger and thrust arises together. Vimlendryata sargau malanam laghavam ruchih/kshutritsahodayah shuddha hrudayodgarkanthatah//vyadhi mardava mutsahastandranashaschya langhite//A.h.su 14/17, According to Asthang Hridaya, proper sign of Langhan is Purity in all sense organs, proper excretion of all byproducts like flatus, urine and faeces, lightness in body, appreciation of taste, Hunger and thrust arises together, purity in heart, Udgara and Kanta, decrease in intensity of disease, Feeling of fresh, remove dullness and drowsiness. Srishta maruta vidmutram kshutpipasasaham laghum/ prasannatmendriyam kshaamam naram viddhatam sulanghitam// Su. U. A 39/104

According to Sushrut, proper sign of Langhan is proper excretion of faeces, flatus and urine, intolerable arise of Hunger and thrust, lightness in body, feeling happiness of all senses and soul, thinness in body.

punyapradou hi aamadoshaharo analakarah sadaa; spoortidascha upavaso indriyannam prasadaaka.

The biological responses of these Upavasa has been well mentioned in dharma shastra i.e. ( punya) auspiciousness, digest ama Dosha, improves digestive fire, induces smartness, brings clarity of senses .In this article we will explore Samyak Langhan Lakshan mentioned by Charak in Charak Sutra Sthan.

\section{Vat and Purisha visharga - proper excretion of flatus and faeces}

The amount of gas depends on the composition of the colonic flora. Colonic bacteria produces gas by fermentation of unabsorbed food residues arriving into the colon, faecal retention would prolong the fermentation process, increasing gas production ${ }^{1}$. In normal human, even very high rates of gas infusion into the small intestine $(30 \mathrm{~mL} / \mathrm{min})$ is tolerated without complaints of pain or bloating and harmlessly passed as flatus per rectum ${ }^{2}$. Gas goes down in the gastrointestinal tract is more effective in the erect position, opposing flotation forces, than when supine ${ }^{3}$.Intestinal gas is composed of varying quantities of exogenous sources and endogenous sources ${ }^{4}$.The exogenous gases are swallowed (aerophagia) when eating or drinking or increased swallowing during times of excessive salivation (as might occur when nauseated or as the result of gastro esophageal reflux. The endogenous gases are produced due to fermentation of by-product of digested certain types of food, or of incomplete digestion by yeast normally or abnormally present in the gastrointestinal tract ${ }^{5}$. Smell of gas can also be caused by the presence of large numbers of micro flora bacteria or the presence of faeces in the rectum. Diets high in protein, especially sulfur-containing amino acids, have been demonstrated to significantly increase the smell of flatus. Normal flatus volume is 476 to $1491 \mathrm{~mL}$ per 24 hours ${ }^{6}$. Different diet produces different microbial colony in gut, which causes different gases and diseases ${ }^{7}$. A study on microbial colony related with Ramadan fasting, indicates increased amounts of Akkermansia muciniphilia (signature of metabolic health) at the end of the fasting period (approximately one month) ${ }^{8}$. The close relationship between diet, the gut microbiome, and health suggests that we may possibly improve movement of flatus and faeces by Langhana (fasting) and modulating our diet. 


\section{DISCUSSION}

Discussion - Vat and Purisha Visharga - proper excretion of flatus and faeces, is mainly depend on digestive fire and gastrointestinal gas produced by gut microbes. The close relationship between diets, the gut microbiome suggests that we may possibly improve movement of flatus and faeces by Langhana (fasting).

2. Udgara Suddhi and Kantha Suddhi - purity in eructation / burping Udagar and Kanth Dusti is totally related by gastric content coming from stomach. That content may be different types.

A. Gastro esophageal reflux- Gastric content is disallowed from entering the esophagus by the esophagogastric junction formed by the lower esophageal sphincter and the crural diaphragm? Despite this barrier between the stomach and the esophagus, gastric content often flows from the stomach into the esophagus the phenomenon is called gastro esophageal reflux ${ }^{9}$. Gastro esophageal reflux episodes cause complaints such as retrosternal pain, heartburn, and regurgitation, or mucosal damage ${ }^{10}$.

B. Belching - With each swallow, air enters the esophagus and is transported to the stomach. Distension of the stomach, such as caused by swallowed air, triggers a reflex during which gas is push out from the stomach into the esophagus, after which it can be expelled orally ${ }^{11}$. This type of belching referred to as gastric belching.

C. Rumination - Rumination is the regurgitation of recently ingested food, which, naturally, is not lead by vomiting and nausea. In ruminant animals, this is a physiologic process which aids in the digestion and absorption of food. On the other hand, if rumination occurs repetitively in humans, this is considered pathological and the condition is known as the rumination syndrome ${ }^{12}$.

Discussion - Udgar Shuddhi and Kanth Suddhi is directly associated with Gastro esophageal reflux, belching and rumination. these all are also depending on quality of gastric fire that can be also corrected by fasting.

\section{Mutra Visarge - proper excretion of urine}

As we know, Functions of the kidneys include removing waste (i.e., urea, uric acid), reabsorbing nutrients (like glucose, amino acid, bicarbonate, sodium etc), and maintaining $\mathrm{pH}$ balance, Osmolality regulation (body's electrolyte water balance), Regulating blood pressure, Secretion of active compounds (like erythropoietin, rennin, calcitriol).main symptoms of nephrotic syndrome is puffy eyes, increased cholesterol levels, fluid in the lungs, anemia and symptoms like headache, tiredness, nausea, swollen leg, itchy skin is found in diabetic nephropathy. Hypertension is both an important cause and result of chronic kidney disease ${ }^{13}$. The positive effect of the complete water fasting was reflected in the reduction of oxidative stress, body weight and blood pressure ${ }^{14}$.Fasting can also check the growth of Polycystic Kidney Disease ${ }^{15}$.

Discussion- Mutra Visarge or proper excretion of urine depends on kidney function. Kidney function is affected by several factors like diabetes, blood pressure, polycystic kidney disease, etc. significant effects have been seen by Langhan on those diseases and other related factors.

\section{Laghava - lightness in body}

Caloric restriction and intermittent fasting (IF) result in similar degrees of weight loss and improvement in insulin sensitivity. IF may have beneficial effects on weight, body composition, cardiovascular biomarkers, and ageing. At the cellular level, IF may also increase resistance against oxidative stress, decrease inflammation, and promote longevity ${ }^{(16)}$. Based on the qualitative analysis, intermittent fasting was found to be efficient in reducing weight, irrespective of the body mass index ${ }^{(17)}$. Several studies show, different fasting pattern appears to result in weight loss as well as reductions in glucose and insulin concentrations ${ }^{(18)}$. Discussion- Adiposity may also cause adipocyte and adipose tissue anatomic and functional abnormalities, termed as adiposopathy or "sick fat." Because, the gastric fire Jatharagni regulates all Dhatvagni (metabolism), this "sick fat "or Dushit Medo Dhatu also arises due to distorted digestive fire. During Langhana (complete fasting/Light diet), food is not available for digestion; the Agni metabolize the ama 
and Sama Doshas ('sick fat') and resulting in Agni Deepana (increase in gastric fire) and Amapachana (digestion of undigested food). Finally, the body becomes Laghu and healthy.

\section{Hrudaya Shuddhi -}

Control of the daily food intake results in weight loss, which is also, associated with better health outcomes including triglycerides, total cholesterol, low-density lipoprotein cholesterol, blood pressure, glucose, insulin, and C-reactive protein ${ }^{17}$. The IF diet limits the development of cardiovascular diseases. Fatty acids and ketenes become the main energy fuel, because the body undergoes metabolic switching of glucoseketene (G-to-K). By moving the biochemical conversion of lipids, it decreases body mass and has a positive influence on lipid profile parameters, and it reduces the concentration of total cholesterol, triglycerides, and LDL cholesterol ${ }^{19}$. IF has been shown to improve ischemic cardiac injury, age-related cardiac hypertrophy, doxorubicin-induced cardio toxicity and risk factors for coronary heart disease. Therefore, IF may be considered as a potential intervention for certain forms of human heart disease $^{20}$.

Discussion- fasting reduces the concentration of total cholesterol, triglycerides, VLDL, LDL cholesterol, i.e. the main cause of atherosclerosis or arterial health. Marked reduction in blood pressure by Langhan also contributes in maintaining cardiac health.

\section{Tandra Klame Gate - Feeling of fresh, removes dullness and drowsiness}

The antidepressant effects of calorie restriction might be based on the molecular basis that involves orexin signaling, p-CREB/BDNF signaling and other neuroendocrine system ${ }^{21}$. One study shows Significant decreases in tension, anger, confusion and total mood disturbance and improvements in vigor were observed in participants in the FCR (fasting \& calorie restriction) group compared to the control group ${ }^{22}$. Short-term fasting in inpatients with pain and stress syndromes is safe and well tolerated. Prolonged fasting as a method of mood enhancement in chronic pain syndromes ${ }^{22}$.
Discussion- Orexins, also known as hypocretins, are two neuropeptides secreted from the lateral hypothalamus. Orexin/receptor regulates many physiological processes, especially feeding behavior, sleep-wake rhythm, reward and addiction and energy balance. Orexin/receptor pathways are also concerned in pathological of many neurological diseases such as narcolepsy, depression, ischemic stroke, drug addiction and Alzheimer's disease (AD). Learning and memory impairments, mainly through activating the hippocampal neuronal cAMP/PKA-CREB (cyclic adenosine monophosphate response element binding protein)/ BDNF (brain-derived neurotrophic factor) signaling pathways. Fasting gives marked effect on orexin and, p-CREB/BDNF signaling.

\section{Swede Jate - Appearance of swat}

It is plausible to assume that the skin, as the fundamental protective barrier against water and heat $\operatorname{loss}^{23}$. One of the main functions of the stratum corneum is to provide a permeability barrier to protect against excess water loss. Extracellular lipids formed primarily of ceramids, cholesterol, and fatty acids are the fundamental components of this barrier. The synthesis of cholesterol necessary for barrier formation takes place in the epidermis ${ }^{24}$. All these changes facilitated the skin to maintain thermal homeostasis under conditions of restricted energy intake ${ }^{25}$. Chronic caloric restriction decreased the glycation rate (responsible for ageing) of skin proteins, resulting in the reduction of age-related accumulation of these metabolites in cutaneous collagen $^{26}$. Caloric restriction without deficiency of essential nutrients has been linked to enhancement of lifespan and decreased aging ${ }^{27}$. Insulin-like growth factor 1 (IGF-1), also called somatomedin C, is known for its pro-growth effects which include suppression of apoptosis (a type of programmed cell death), increased angiogenesis (new blood vessels form from pre-existing vessels, and stimulation of cell proliferation. Some study explained by a significant reduction of IGF-1 levels associated with dietary restriction, suggesting a potential anti-carcinogenic role $^{28}$. 
Discussion- Swede Jate or appearance of sweat is related with skin health. Skin health is direct associated with fundamental protective barrier against water and heat loss, i.e. thermal homeostasis, glycation rate (responsible for skin ageing), Insulinlike growth factor 1 (IGF-1), responsible for skin progrowth. Several researches show clear effect of Langhan on those factors.

\section{Ruchau Chaiv - appreciation of taste}

Several means are important for the modulation of taste sensitivity in fasting and satiety states. Firstly, systemic activation of the brain during food stimulus may change sensitivity of the central structures concerned in perception of taste stimuli ${ }^{29}$.Secondly, the efferent influences on gustatory receptors induced by hunger or satiety may change sensitivity of the gustatory receptors. Thirdly, change of the autonomic nervous system activity during fasting state may contribute to perception of taste stimuli ${ }^{30}$.

Discussion- Ruchau Chaiv - appreciation of taste is basically depending on factors like the gustatory system (a sensory system responsible for the perception of taste and flavor. In humans, the gustatory system is comprised of taste cells in the mouth, which sense the five taste modalities: salty, sweet, bitter, sour and umami), several cranial nerves and the gustatory cortex, blood metabolic parameter (specially free fatty acids like caproic, lauric, oleic, linoleic, and linolenic acid). fasting have a significant effect on gustatory system, blood metabolic parameter and other factors.

\section{Khut Pipas Sah Udaye- Hunger and thrust arises together.}

As the gut empties, we are ready to eat again. We typically refer to this absence of fullness as 'hunger', but in this state, even when it is delayed (e.g. by missing one or two meals), our mental and physical performance is not compromised because body energy stores are organized to maintain energy supply to our brain and muscles ${ }^{31}$. The physical sensation of hunger is related to contractions of the stomach muscles. These contractions, sometimes called hunger pangs once they become severe, are believed to be triggered by high concentrations of the ghrelin hormone ${ }^{32}$. The hormones Peptide YY and Leptin can have an opposite effect on the appetite, causing the sensation of being full. Ghrelin can be released if blood sugar levels get low, a condition that can result from long periods without eating. None of these answers, however, include the eating equivalent of the physical sensation of a dry mouth and throat ${ }^{33}$, that signals thirst, and none of them are at all similar to the tempting hunger for air that is experienced when breathing is prevented ${ }^{34}$. A ketogenic diet, as being low in carbohydrate, means that your body will not retain water as it did when fueled by carbohydrates. When you eat high in carbohydrates, your body will store the excess as glycogen. Glycogen binds to water and you will retain water in your body. When you switch to a low carbohydrate or ketone diet you will use up the glycogen stores, that by a process called gluconeogenesis, is converted in glucose and the water that was attached to the glycogen will be released, and you will lose water (hence the rapid weight loss that most people notice initially). Now, as you transition into Ketosis your body still needs water to make use of any glycogen you might eat or create, but there's none in your system. And so, it sends the signal that we need more water! And you feel thirsty ${ }^{35}$.

Discussion: Ghrelin is a versatile gut hormone commonly called "hunger hormone". Ghrelin stimulates the brain, which leads to an increase in appetite, and it slows metabolism and decreases the body's ability to burn fat. Ghrelin also favors the gathering of fatty tissue in the abdominal area. The hormones Peptide YY and Leptin can have an opposite effect on the appetite, causing the sensation of being full. Sign of proper Langhan as Khut Pipas Sah Udaye (i.e. Hunger and thrust arises together) is due to increase of ghrelin hormone and glyconeogenesis simultaneously.

\section{CONCLUSION}

Vat and Purish Vishaga is mainly depending on colonial bacteria, present in gastrointestinal track that can be affected by Fasting. Udgar shuddhi and kanth suddhi is directly associated with Gastro esophageal 
reflux, belching and rumination that can be also corrected by fasting. Mutra Vishaga is mainly due to kidney function, fasting shows significant effect on $\mathrm{pH}$ balance, hypertension, osmolality and oxidative stress. Laghava or lightness in body is well established by effect of fasting on obesity. Positive influence on lipid profile parameters indicates Hruday Suddhi. Significant decrease in tension, anger, confusion and total mood disturbance and improvements in vigor by intermittent fasting shows sign of Tandra Klame gate. Maintaining thermal homeostasis by skin, decrease in glycation rate of skin protein, reduction of IGF-1 levels by fasting shows sign of swede jate (appearance of swat). The Sign, Ruchau Chaiv or appreciation of taste is influenced by gustatory system that can be corrected by fasting. Finally, Khut Pipas Sah Udaye or arise of Hunger and thrust together, may directly associated with ghrelin hormone and glycogen metabolism (glycogen and water binding), that is directly affected by Langhan or fasting.

\section{REFERENCES}

1. Azpiroz F, Intestinal gas dynamics: mechanisms and clinical relevance, Gut 2005 Jul; 54(7):893-895.

2. King $\mathrm{T}$ S, Elia $\mathrm{M}$, Hunter $\mathrm{J}$ O. Abnormal colonic fermentation in irritable bowel syndrome. The Lancet. 1998 Oct 10; 352 (9135): 1187-9.

3. Dainese R, Serra J, Azpiroz F, et al. Influence of body posture on intestinal transit of gas. Gut 2003; 52:971974.

4. "Gas in the Digestive Tract". National Institute of Diabetes and Digestive and Kidney Diseases. Retrieved August 24, 2015.

5. Tomlin J, Lowis C, Read N W. Investigation of normal flatus production in healthy volunteers. Gut 1991 June; 32 (6): 665- 669.

6. Tangerman A. Measurement and biological significance of the volatile sulfur compounds hydrogen sulfide, methanethiol and dimethyl sulfide in various biological matrices. Journal of Chromatography B 2009; 877 (28): 3366-3377.

7. Duncan S H, et al. Human colonic microbiota associated with diet, obesity and weight loss. Int J Obes (Lond). 2008. 32(11):1720-1724.
8. Karakan T. Intermittent fasting and gut microbiota. Turk J Gastroenterol 2019; 30(12): 1008. 9. Kessing $\mathrm{BF}$, Smout AJPM. Reflux, belching, rumination and their interrelationships. University of Amsterdam.2015; 11-14.

9. Dent J, Holloway RH, Toouli J, Dodds WJ. Mechanisms of lower oesophageal sphincter incompetence in patients with symptomatic gastrooesophageal reflux. Gut. 1988; 29(8):1020-8.

10. Wyman JB, Dent J, Heddle R, Dodds WJ, Toouli J, Downton J. Control of belching by the lower oesophageal sphincter. Gut. 1990; 31:639-646

11. Tack J, Talley NJ, Camilleri M, Holtmann G, Hu P, Malagelada J-R. Functional gastroduodenal disorders. Gastroenterology. 2006; 130(5):1466-79.

12. Tedla F M, Brar A, Browne R, Brown C. Hypertension in Chronic Kidney Disease: Navigating the Evidence. Int J Hypertens. 2011;1-6.

13. Mojto V, Gvozdjakova A, Kucharska J, Rausova Z, Vancova O, Valuch J. Effects of complete water fasting and regeneration diet on kidney function, oxidative stress and antioxidants. Bratisl Lek Listy. 2018; 119(2):107-111.

14. Warner G, Hein KZ, Nin V, Edwards M, Chini CCS, Hopp K, Harris PC, Torres VE, Chini EN. Food restriction ameliorates the development of polycystic kidney disease. J Am Soc Nephrol. 2016;27: 14371447.

15. Stockman M, Thomas D, Burke J, et al. Intermittent Fasting: Is the Wait Worth the Weight? Curr Obes Rep. 2018; 7:172-185.

16. Kavitha Ganesan, Yacob Habboush, Senan Sultan. Intermittent Fasting: The Choice for a Healthier Lifestyle. Cureus. 2018 Jul; 10(7): e2947.

17. Patterson RE, Laughlin GA, LaCroix AZ, et al. Intermittent Fasting and Human Metabolic Health. J Acad Nutr Diet. 2015;115(8):1203-1212.

18. Malinowski B, Zalewska K, Węsierska A, Sokołowska M M, Socha M, Liczner G, Pawlak-Osińska K., Wiciński M. Intermittent Fasting in Cardiovascular Disorders-An Overview. Nutrients. 2019; 11(3): 673.

19. Zhu H, He L. Cardioprotective Effects of Intermittent Fasting. J Clin Diagn Res.2017; 5:1.

20. Zhang Y, Liu C, Zhao Y, Zhang X, Li B, Cui R. The Effects of Calorie Restriction in Depression and Potential Mechanisms. Curr Neuropharmacol. 2015; 13(4):536-542.

21. Hussin N M, Shahar S, Teng N I, Ngah W Z, Das S K. Efficacy of fasting and calorie restriction (FCR) on 
mood and depression among ageing men. J Nutr Health Aging. 2013.17(8):674-680.

22. Bragazzi N L., Sellami M., Salem I, Conic R, Kimak M, Pigatto P, Damiani G. Fasting and Its Impact on Skin Anatomy, Physiology, and Physiopathology: A Comprehensive Review of the Literature. Nutrients.2019; 11(2): 249.

23. Hunt N.D, Li G.D, Zhu M, Miller M, Levette A, Chachich M.E, Spangler E.L, Allard J.S, Hyun D.H, Ingram D.K., et al. Effect of calorie restriction and refeeding on skin wound healing in the rat. Age (Dordr.). 2012; 34:1453-1458.

24. Hayati F, Maleki M, Pourmohammad M, Sardari K, Mohri M, Afkhami A. Influence of Short-term, Repeated Fasting on the Skin Wound Healing of Female Mice. Wounds. 2011; 23(2): 38-43.

25. Cefalu W T, Bell-Farrow A D, Wang Z Q, Sonntag W $\mathrm{E}, \mathrm{Fu} \mathrm{M} \mathrm{X}$, Baynes J W, Thorpe $\mathrm{S}$ R. Caloric restriction decreases age-dependent accumulation of the glycoxidation products, $\mathrm{N}$ epsilon(carboxymethyl)lysine and pentosidine, in rat skin collagen. J. Gerontol. A Biol. Sci. Med. Sci. 1995;50: B337-B341.

26. Bhattacharyya T K., Merz M, Thomas J R. Modulation of cutaneous aging with calorie restriction in Fischer 344 rats: A histological study. Arch. Facial Plast Surg. 2005; 7:12-16.

27. Xie L, Jiang Y, Ouyang P, Chen J, Doan H, Herndon B, Sylvester J E, Zhang K, Molteni A, Reichle M, et al. Effects of dietary calorie restriction or exercise on the PI3K and Ras signaling pathways in the skin of mice. J Biol Chem. 2007; 282:28025-28035.

28. Sudakov KV. Brain neuronal mechanisms of motivation and reinforcement: systemic organization of behavior. Integr Physiol Behav Sci, 1993; 28: 396-407.

29. Sulimov A V. The hunger dominant in man and the reactions of the autonomic nervous system. Zh Vyssh Nerv Deiat Im I P Pavlova, 1993; 43: 707-12.

30. Rogers P J, Ferriday D, Jebb S A, Brunstrom J. Connecting biology with psychology to make sense of appetite control. Nutrition Bulletin. 2016; 41(4): 344352.

31. Pradhan G, Samson S L, Sun Y. Ghrelin: much more than a hunger hormone. Curr Opin Clin Nutr Metab Care. 2013; 16(6): 619-624.

32. Rolls B J, Wood R J, Rolls E T, Lind H, W Lind, Ledingham J G G. Thirst following water deprivation in humans. Am J Phys. 1980; 239(5): R476-R482.
33. Levitsky D A. The non-regulation of food intake in humans: hope for reversing the epidemic of obesity. Physiol Behav. 2005; 86:623-632.

34. Mackay E M, Bergman H C. The relation between glycogen and water storage in the liver. J Biol Chem. 1932.96:373-380.

\section{Source of Support: Nil \\ Conflict of Interest: None Declared}

How to cite this URL: Akhilesh Kumar Singh: Interpretation And Co-Relation Of Samyak Langhan Lakshan In Charak Samhita With Contemporary Sciences. International Ayurvedic Medical Journal \{online\} 2020 \{cited October, 2020\} Available from: http://www.iamj.in/posts/images/upload/4794_4800.pdf 